\title{
THE VALIDITY OF CLINICAL DIAGNOSES OF DEMENTIA IN A GROUP OF CONSECUTIVELY AUTOPSIED MEMORY CLINIC PATIENTS
}

\author{
B.E. GAY'1, K.I. TAYLOR¹, U. HOHL², M. TOLNAY², H.B. STAEHELIN1
}

\begin{abstract}
Geriatric University Clinic, University Hospital Basel, Switzerland; 1. Geriatric University Clinic, University Hospital Basel; 2. Department of pathology, University Hospital Basel, 3Neurological Clinic, University Hospital Bern, Switzerland, Please address correspondence to: Dr. Beatrice Gay, Boveresses 84, 1010 Lausanne, Tel 0041216525100 , Fax 00412165251 00, e-mail: beatrice.gay@chuv.ch
\end{abstract}

\begin{abstract}
Background: Epidemiological studies show that up to $10 \%$ of individuals aged 65 years and older suffer from dementia, most commonly from dementia of the Alzheimer Type (DAT) [1]. Clinicopathological studies are critical to our understanding of this disease and improving the accuracy of clinical diagnoses. Objectives: Our objectives were to examine the validity of clinical diagnoses of DAT, to determine the prevalence of different forms of dementia in this sample, and to investigate the relationship between age at death and polymorbidity. Subjects and method: Clinical data were available from 221 patients who had been examined at the Basel Memory Clinic between 1986 and 1996. From this population, 34 \% (75 patients) were autopsied in the Department of Pathology, University Hospital Basel, and neuropathological examinations were additionally performed on $62(83 \%)$ of these patients. Clinical and neuropathological data were retrospectively compared. Results: $67.8 \%$ of the neuropathologically examined patients received a definitive diagnosis of AD (Alzheimer's disease), vascular dementia $(\mathrm{VaD})$ or mixed dementia $(\mathrm{AD}$ and $\mathrm{VaD})$. $\mathrm{AD}$ alone or with other histopathological hallmarks of dementia was the most prevalent neuropathological diagnosis $(63 \%)$. VaD was deemed the only cause of dementia in only $4.8 \%$ of patients. The sensitivity for DAT was $75.9 \%$, the specificity $60.6 \%$. Increasing age was associated with an increasing number of clinical and neuropathological diagnoses. Conclusion: The sensitivity and specificity of the clinical diagnoses of DAT found in our study are similar to previous reports (2-5). Older patients had more etiologies of their dementia than younger patients. This study reaffirms the need for internationally accepted criteria for clinical and neuropathological diagnoses, as well as further clinical-neuropathological investigations to further refine the clinical diagnostic process.
\end{abstract}

Key words: Dementia, clinical diagnosis, memory clinic.

\section{Introduction}

Epidemiological studies have demonstrated that up to $10 \%$ of individuals aged 65 years or older suffer from dementia, most commonly from dementia of the Alzheimer type (DAT) (1). Since our lifespans are increasing $(2,6)$, the relationship between age and the prevalence of dementia suggests that memory clinics and similar institutions will face a growing challenge in the coming decades to identify the increasing number of affected individuals. While the diagnosis of patients in the late stages of the disease is straightforward, it is difficult to distinguish early-stage dementia from healthy aging and from depression.

During the first decades of the last century, vascular dementia (VaD) was cited as the most common cause of dementia (7). However, many prospective clinicopathological studies have since shown that $\mathrm{AD}$ is the most common cause of dementia in the elderly (8). Based on recent clinicopathological studies, dementia with Lewy bodies (DLB) has emerged as the second most common degenerative pathology associated with dementia, accounting for $10-25 \%$ of all cases (9-12). Vascular pathology now appears to be the third most common cause of dementia, accounting for roughly one-fifth of the number of dementia cases $(13,14)$. However, the situation is not quite as simple as this breakdown suggests, since vascular pathology and $\mathrm{AD}$ often occur together to varying extents, a syndrome called mixed dementia. Whether cognitive impairments due to diastolic hypotension contribute to the development of $\mathrm{VaD}$ or DAT remains to be established $(6,15)$. Furthermore, it has become increasingly clear that various non-Alzheimer degenerative conditions characterized by frontotemporal lobar degeneration (FTLD) like frontotemporal dementia account for $12-20 \%$ of all dementia cases (16-18). More recently, argyrophilic grain disease $(\mathrm{AgD})$ has been described as a lateonset form of dementia accounting for roughly $5 \%$ of dementia cases (19). However, many other, rarer forms of degenerative dementias exist, among them senile dementia with tangles (2022). Although these entities have been subsumed in the FTLD nomenclature, they have distinct clinical and pathological features.

The accurate clinical diagnosis of dementia is becoming increasingly relevant as new treatment possibilities for neurodegenerative disorders become available. However, the clinical diagnosis remains an estimation of the underlying neuropathology until the definitive diagnosis is established upon autopsy. Studies investigating the diagnostic accuracy for dementia have reported rates between 52 and $100 \%$ for DAT $(2-4,23-26)$ and between 21 and $95 \%$ for $\operatorname{VaD}(2-4,23,25-$ 27). However, these studies included younger patients with few comorbidities. The objectives of the present study were to 
determine the clinical diagnostic accuracy in a group of older patients examined at the Memory Clinic University Hospital Basel, Switzerland by comparing the clinical with the neuropathological diagnoses, to determine the prevalence of the different forms of dementia, and to investigate the relationship between age at death and polymorbidity. The "gold standard" for the determination of diagnoses was the neuropathological findings.

\section{Patients and methods}

\section{Memory Clinic}

The aim of the Memory Clinic (MC) at the University Hospital Basel, Switzerland, is to detect dementing disorders in ambulatory elderly patients in an early stage of illness. The clinical diagnostic process has been described elsewhere (28). In the present study, we used the Mini Mental State examination (MMS) to describe the severity of dementia [29] and the Hachinski Ischemic Score (HIS) to assess cerebrovascular morbidity (30).

\section{Patients}

Two hundred and twenty-one patients who had been examined at the MC died during the observation period of the current study (1986-1996). Between 1988 and 1997, $34 \%$ (75 patients) were autopsied in the Department of Pathology, University Hospital Basel, and $83 \%$ of these patients $(n=62)$ additionally underwent a neuropathological examination. The study sample comprised 28 men and 34 women, their age at death ranged between 58 and 97 years (mean age \pm standard deviation $(\mathrm{SD})=78.7 \pm 8.2$ years $)$, and their mean MMS score was $20(\mathrm{SD}=6.3)$ an average of 3.2 years $(\mathrm{SD}=2.3$ years $)$ preceding death.

The clinical diagnosis of DAT relied on DSM-IV (the Diagnostic and Statistical Manual of mental disorders IV) (31) and NINCDS-ADRDA criteria (National Institute of Neurological and Communicative Disorders and Stroke and the Alzheimer's Disease and Related Disorders Association) (32). $\mathrm{VaD}$ was diagnosed using NINDS-AIREN criteria (National Institute of Neurological Disorders and Stroke in collaboration with L'Association Internationale pour la Recherche et l'Enseignement en Neurosciences) (33), and published consensus guidelines were employed to reach FTD (16) and DLB (9) diagnoses. The diagnosis of Parkinson's disease relied on the cardinal symptoms of resting tremor, rigor and akinesia or hypokinesia. AAMI was diagnosed according to the criteria of Levy (45). Revised diagnoses, if made in the follow-up visit scheduled one year after the first consultation, were employed in the present study.

\section{Neuropathology}

Brains were immersed in $4 \%$ phosphate buffered formaldehyde ( $\mathrm{pH}$ 7.4) for 2 weeks. After fixation, the brains were sliced in the coronal plane and several tissue blocks were taken from various parts of the brain and embedded in paraffin. For the present study, we examined the following regions in detail: the anterior hippocampus including the head and body of the cornu ammonis, dentate gyrus, subiculum, entorhinal and perirhinal cortices and parts of the gyrus fusiformis near the rhinal sulcus. The posterior hippocampal region included the body and tail of the cornu ammonis, the dentate gyrus the subiculum and the parahippocampal gyrus with adjacent temporobasal neocortex. Further regions investigated included the frontal, fronto-orbital, rostral cingulate and occipital cortices, the striatum, the amygdala, the medial forebrain nuclei including the septal nuclei, various cerebral white matter regions, the substantia nigra, the cerebellum and the brainstem including the locus coeruleus and medulla oblongate. Histological sections were stained with haematoxilin and eosin, Holmes-Luxol, periodic acidic methamine silver stain for senile plaques, and the Gallyas silvertechnique [34] for argyrophilic neurofibrillary lesions. Histology was complemented by various immunohistochemical stainings with antibodies against phosphorylated tau (AT8), amyloid-beta protein, alphasynuclein and ubiquitin. The neuropathological diagnosis was made based on published diagnostic criteria [35, 41]

\section{Statistical method}

Because of heterogeneity of diagnoses in the patient group and the small cell sizes, we report mainly descriptive statistics. The Chi-square test was employed to compare the distributions of patients in different diagnostic groups and was calculated with Statview, version 5, for Windows (www.statview.com/ product/techoverview.shtml).

\section{Results}

\section{Demographic data}

Table 1 summarizes the patients' demographic data and neuropathological diagnoses. The mean age at death of the 38 men and 34 women was $78.7 \pm 8.2$ years. Before the first consultation, the duration of symptoms varied between less than six months to over 5 years, and did not appear to be related to the diagnosis. The mean duration between the first MC consultation and death was $3.2 \pm 2.3$ years. The AD group survived the longest after the first MC consultation (4.1 years). The AD group (and four patients with $\mathrm{AgD}$ ) scored lowest on the MMS, reflecting their primary neocortical impairments and/or the more advanced stage of their disease.

\section{Relationship between clinical and pathological diagnoses}

The relationships between the clinical and neuropathological diagnoses are shown in Table 2. 67.8\% $(n=42)$ of patients received a neuropathological diagnosis of $\mathrm{AD}, \mathrm{VaD}$ or mixed dementia ( $\mathrm{AD}$ and $\mathrm{VaD})$ and $\mathrm{AD}+\mathrm{DLB}$. $\mathrm{AD}$ was the most frequent diagnosis; $63 \%$ of patients $(n=39)$ evidenced neuropathological signs of AD, either in isolation $(n=29)$ or with other histopathological hallmarks of dementia (e.g. VaD). 


\section{THE VALIDITY OF CLINICAL DIAGNOSES}

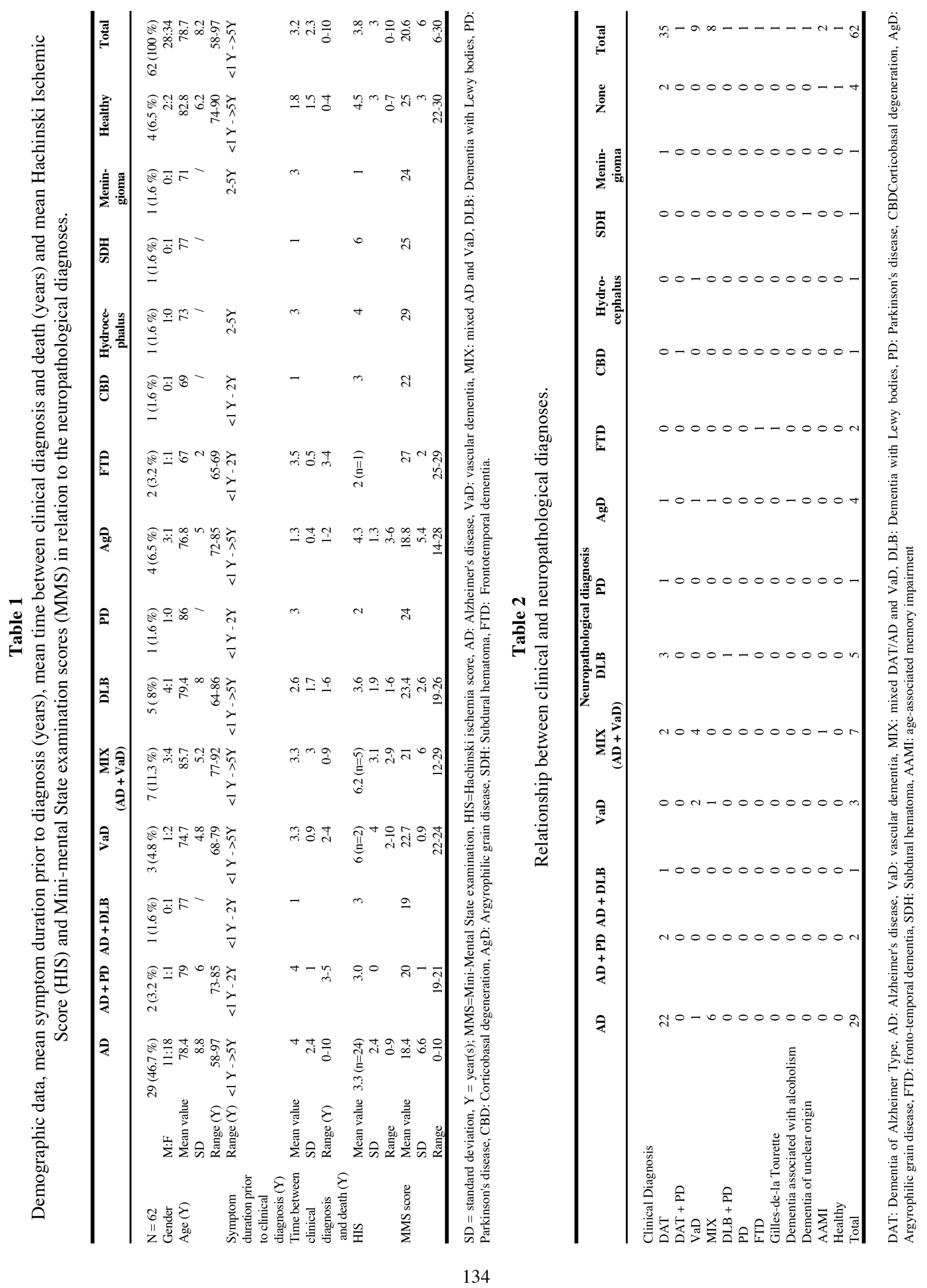


Among the 29 AD cases, the Braak stage (42) and CERAD plaque score (43) where as follows: Braak stage IV $(n=6), V$ $(n=6)$ and VI $(n=17)$, CERAD plaque score $C(n=29)$. Thus, according to the NIA-Reagan criteria [44] there was a high ( $\mathrm{n}=$ $23)$ or intermediate to high $(n=6)$ likelihood that dementia was due to $\mathrm{AD}$ lesions in all our AD patients. Only $4.8 \%$ of patients $(n=3)$ were diagnosed with $\mathrm{VaD}$. The prevalence of DLB $(8.1 \%)$ and FTD $(3.2 \%)$ was lower than reported values $(10-25 \%$ and $12-20 \%$, respectively) $(14-17,21)$. This difference may be attributable to geographical factors, as epidemiological studies conducted in England or Scandinavia report higher prevalence rates for DLB and FTD.

Sensitivity and specificity of the clinical diagnosis of DAT

Despite the small cell sizes, the sensitivity and specificity of the clinical diagnoses of DAT were estimated. Sensitivity refers to the true positive rate, i.e. the number of patients having both a clinical and neuropathological diagnosis of disease A divided by the total number of patients having the neuropathological diagnosis of disease A. Specificity refers to the true negative rate, i.e. the number of patients having clinical and neuropathological diagnosis other than diagnosis A divided by the total number of patients with a neuropathological diagnosis other than diagnosis A. The sensitivity and specificity of the clinical diagnosis of DAT in the present sample were $75.9 \%$ and $60.6 \%$, respectively, and are similar to those reported in previous studies (2-5).

\section{Age at death and polymorbidity}

To evaluate the relationship between polymorbidity and age, the sample of patients was split at the median age of 78 into younger and older groups, and the corresponding numbers of patients with no neuropathology, one neuropathological diagnosis and more than one neuropathological diagnosis were tabulated (see Table 3). Chi-squared analyses revealed that while the frequencies of patients with single neuropathological diagnoses were comparable in the younger and older groups $\left(\chi^{2}(\mathrm{df}=1)=.03 ; \mathrm{p}=\mathrm{ns}\right)$, significantly more older than younger patients were diagnosed with multiple neuropathological diagnoses $\left(\chi^{2}(\mathrm{df}=1)=4.26\right.$; $\left.\mathrm{p}<0.05\right)$.

Table 3

Comorbidities with advancing age.

\begin{tabular}{lcccc}
\hline \multicolumn{4}{c}{ Age at death } \\
\hline $\begin{array}{l}\text { Number of neuropath- } \\
\text { ological findings }\end{array}$ & $<78$ Jahre & $>78$ Jahre & Total & $\chi^{2}$ \\
0 & 1 & 3 & 4 & \\
1 & 20 & 19 & 39 & .03 \\
$>1$ & 5 & 14 & 19 & 4.26 \\
Total & 26 & 36 & 62 & \\
\hline
\end{tabular}

\section{Discussion}

The most common neuropathological diagnosis in the present patient population was $\mathrm{AD}$, either alone or associated with other lesions, in $63 \%$ of all patients. $34 \%$ of patients suffered from pure AD. The next most common cause of dementia was the mixed etiology ( $\mathrm{AD}$ and $\mathrm{VaD}$ ) with $11.3 \%$, followed by $\mathrm{DLB}(8 \%)$ and $\mathrm{AgD}$ in $6.5 \%$, and $\mathrm{VaD}$ in $4.8 \%$ of the patients. These results are consistent with previous neuropathological studies (see Table 5). Moreover, the DLB prevalence of $8 \%$ is consistent with other reports from hospital-based populations, which typically range from 10 to $15 \%(9,10,12)$. Other causes of dementia (CBD, FTD, meningioma, hydrocephalus, PD and subdural hematoma) were found in $11.2 \%$ of the patients. Four patients $(6.5 \%)$ had no pathological findings on autopsy. One of these patients (Braak stage II) had been considered neurologically normal, one patient had been clinically diagnosed with a subcortical dementia syndrome with an ataxic gait, one patient (Braak stage III) had been clinically diagnosed with AAMI, and one patient had been clinically diagnosed with a depressive disorder with frontal lobe dysfunction and showed status lacunaris on MRI which was not confirmed in the neuropathological examination.

Table 4

Reported prevalence of the different forms of dementia.

\begin{tabular}{lcccc}
\hline & AD & mixed & VaD & DLB \\
\hline Mölsä et al., 1985 [2] & $48.3 \%$ & $10.3 \%$ & $19.0 \%$ & 0 \\
Jellinger et al., 1990 [4]: & & & & \\
Psychiatric population & $69.4 \%$ & $8.8 \%$ & $9.5 \%$ & $0.7 \%$ \\
Geriatric population & $59.7 \%$ & $6.8 \%$ & $16.6 \%$ & 0 \\
General population & $56.5 \%$ & $8.7 \%$ & $18.3 \%$ & $1.3 \%$ \\
Drach et al., 1997 [36] & $35.6 \%$ & $15.3 \%$ & $5.1 \%$ & $13.6 \%$ \\
Knopman et al., 2003 [8] & $51.0 \%$ & $12.4 \%$ & $13.5 \%$ & $10.1 \%$ \\
Gay et al., current study & $46.7 \%$ & $11.3 \%$ & $4.8 \%$ & $8.0 \%$ \\
\hline
\end{tabular}

In the present study, the sensitivity of the clinical diagnosis of DAT was $75.9 \%$ and the specificity $60.6 \%$. In Table 5, we compare the present results with those reported in other studies. The relatively low specificity in the cited studies, i.e. the discrepancy between the positive clinical findings and the results of the neuropathological examination, indicates a substantial symptomatological variation of associated brain pathology. Lopez et al. (1) reported in a retrospective study an increasing specificity (52 to $80 \%$ ) in the clinical diagnosis of DAT over the last 20 years, while the sensitivity for the diagnosis of DAT remained above $90 \%$. This pattern was attributed to the improvement in the diagnosis of non-DAT dementias.

Table 5

Comparison of sensitivities and specificities of the diagnosis of Dementia of the Alzheimer Type (DAT)

\begin{tabular}{lcc}
\hline & Sensitivity & Specificity \\
\hline Mölsä et al., 1985 [2] & 0.71 & 0.73 \\
Jellinger et al., 1990 [4] & & \\
Psychiatric population & 0.92 & 0.60 \\
Geriatric population & 0.80 & 0.84 \\
General population & 0.82 & 0.78 \\
Galasko et al., [5] 1994 & 0.78 & 0.48 \\
Victoroff et al., [3] 1995 & 0.75 & 0.54 \\
Lim et al., [37]1999 & 0.83 & 0.55 \\
Gay et al., current study & 0.76 & 0.61 \\
\hline
\end{tabular}




\section{THE VALIDITY OF CLINICAL DIAGNOSES}

The diagnosis of DAT appears to be most accurate in published studies: the diagnostic accuracy for of DLB has a low sensitivity and a high specificity $(14,25,26,38)$, and the specificity in diagnosing $\mathrm{VaD}$ ranges from 64 to $98 \%$ while the sensitivity remains low (i.e., 20 to $70 \%)(5,24,27,39)$. The validity of the clinical diagnostic criteria for mixed dementia remains controversial $(14,25,26,38)$.

The present study found that polymorbidity increases with increasing age at death. The diagnosis of patients suffering from multiple dementia etiologies remains a challenging endeavor $(26,39)$. While it seems logical to attribute the dementia to the neuropathologic lesions found, it is worth recalling that even considerable lesions may not cause a clinical dementia syndrome (40).

The patient group in the present study had several biases. Firstly, not every patient had a follow-up examination. Secondly, every patient who was seen in the MC was referred by a physician (practitioner, hospital) for this specialist examination; these patients most likely presented with a complicated clinical picture that necessitated consultation with a specialist center. Thirdly, nearly all patients who underwent autopsy died in a hospital (92\%). Thus, the autopsied subgroup may have suffered from other systemic illnesses and may therefore not be reflective of the memory clinic populations as a whole. In Switzerland, patients who die at home or in an institution are rarely autopsied. Finally, the present cohort included polymorbid patients with acute illnesses or those that suffered from a behavioral disorder, i.e. patients not suited for nursing home placement and who instead required gerontopsychiatric institutionalization.

\section{Conclusion}

The present study investigated the validity of clinical diagnoses of dementia in a group of consecutively autopsied Memory Clinic patients. The sensitivity of the clinical diagnosis for DAT was $75.9 \%$ and the specificity $60.6 \%$. Thus, the present results are similar to those reported in previous studies (2-5). Older patients more commonly suffered from multiple etiologies of dementia than younger patients. This study reaffirms the need for internationally accepted diagnostic criteria for dementia that are sensitive and specific. The neuropathological investigation remains critical for the determination of dementia etiology.

Acknowledgements: The authors thank Mrs. Karin Zehnder for her help in preparing the manuscript. K.I. Taylor was supported by the Swiss Foundation for Ageing Research (financed by the Loterie Romande), the Freiwillige Akademische Gesellschaft, University of Basel, Switzerland, and the Swiss Alzheimer's Association.

\section{References}

1. Lopez OL, Becker JT, Klunk W, Saxton J, Hamilton RL, Kaufer DI, Sweet RA, Cidi Meltzer C, Wisniewski S, Kamboh MI, DeKosky ST. Research evaluation and diagnosis of probable Alzheimer's disease over the last two decades: I. Neurology. 2000;55:1854-62.

2. Molsa PK, Paljarvi L, Rinne JO, Rinne UK, Sako E. Validity of clinical diagnosis in dementia: a prospective clinicopathological study. J Neurol Neurosurg Psychiatry. 1985;48:1085-90.

3. Victoroff J, Mack WJ, Lyness SA, Chui HC. Multicenter clinicopathological correlation in dementia. Am J Psychiatry. 1995;152:1476-84.

4. Jellinger K, Danielczyk W, Fischer P, Gabriel E. Clinicopathological analysis of dementia disorders in the elderly. J Neurol Sci. 1990;95:239-58.

5. Galasko D, Hansen LA, Katzman R, Wiederholt W, Masliah E, Terry R, Hill LR, Lessin P, Thal LJ. Clinical-neuropathological correlations in Alzheimer's disease and related dementias. Arch Neurol. 1994:51:888-95.

6. Skoog I. Psychiatric epidemiology of old age: the H70 study--the NAPE lecture 2003. Acta Psychiatr Scand. 2004;109:4-18.

7. Reed BR. Vascular dementia. Arch Neurol. 2004;61:433-5.

8. Knopman DS. Alzheimer type dementia: In: Dickson DW: the molecular pathology of dementia and movement disorders; 2003.

9. McKeith IG, Galasko D, Kosaka K, Perry EK, Dickson DW, Hansen LA, Salmon DP, Lowe J, Mirra SS, Byrne EJ, Lennox G, Quinn NP, Edwardson JA, Ince PG, Bergeron C, Burns A, Miller BL, Lovestone S, Collerton D, Jansen EN, Ballard C, de Vos RA, Wilcock GK, Jellinger KA, Perry RH. Consensus guidelines for the clinical and pathologic diagnosis of dementia with Lewy bodies (DLB): report of the consortium on DLB international workshop. Neurology. 1996;47:1113-24.

10. Keith I, Fairbaim A, Bothwell R, Moore P, Ferrier I, Thompson P, Perry R. An evaluation of the predictive validity and interrater reliability of clinical diagnostic criteria for senile dementia of Lewy body type. Neurology. 1994;44:872-877.

11. Merdes AR, Hansen LA, Jeste DV, Galasko D, Hofstetter CR, Ho GJ, Thal LJ, Corey-Bloom J. Influence of Alzheimer pathology on clinical diagnostic accuracy in dementia with Lewy bodies. Neurology. 2003;60:1586-90.

12. McKeith I, Mintzer J, Aarsland D, Burn D, Chiu H, Cohen-Mansfield J, Dickson D, Dubois B, Duda JE, Feldman H, Gauthier S, Halliday G, Lawlor B, Lippa C, Lopez OL, Carlos Machado J, O'Brien J, Playfer J, Reid W. Dementia with Lewy bodies. Lancet Neurol. 2004;3:19-28.

13. Skoog I, Nilsson L, Palmertz B, Andreasson LA, Svanborg A. A population-based study of dementia in 85-year-olds. N Engl J Med. 1993;328:153-8.

14. Morris JH. Vascular dementia. In: Esiri MM, Morris JH, The neuropathology of dementia; 2003.

15. Qiu C, von Strauss E, Fastbom J, Winblad B, Fratiglioni L. Low blood pressure and risk of dementia in the Kungsholmen project: a 6-year follow-up study. Arch Neurol. 2003;60:223-8.

16. Brun A, Englund B, Gustafson L, Passant U, Mann D, Neary D, Snowden J. Clinical and neuropathological criteria for frontotemporal dementia. The Lund and Manchester Groups. J Neurol Neurosurg Psychiatry. 1994;57:416-8.

17. Snowden JS, Neary D, Mann DM. Frontotemporal dementia. Br J Psychiatry. 2002;180:140-3.

18. Tolnay M, Probst A. Frontotemporal lobar degeneration--tau as a pied piper? Neurogenetics. 2002;4:63-75.

19. Tolnay M, Clavaguera F. Argyrophilic grain disease: a late-onset dementia with distinctive features among tauopathies. Neuropathology. 2004;24:269-83.

20. Yamada M. Senile dementia of the neurofibrillary tangle type (tangle-only dementia): neuropathological criteria and clinical guidelines for diagnosis. Neuropathology. 2003;23:311-7.

21. Jellinger KA, Bancher C. Senile dementia with tangles (tangle predominant form of senile dementia). Brain Pathol. 1998:8:367-76.

22. Ulrich J, Spillantini M, Goedert M, Dukas L, Staehelin H. Abundant neurofibrillary tangles without senile plaques in a subset of patients with senile dementia. Neurodegeneration. 1992;1:257-264.

23. Sulkava R, Haltia M, Paetau A, Wikstrom J, Palo J. Accuracy of clinical diagnosis in primary degenerative dementia: correlation with neuropathological findings. J Neurol Neurosurg Psychiatry. 1983;46:9-13.

24. Gearing M, Mirra SS, Hedreen JC, Sumi SM, Hansen LA, Heyman A. The Consortium to Establish a Registry for Alzheimer's Disease (CERAD). Part X. Neuropathology confirmation of the clinical diagnosis of Alzheimer's disease. Neurology. 1995;45:461-6.

25. Knopman DS, DeKosky ST, Cummings JL, Chui H, Corey-Bloom J, Relkin N, Small GW, Miller B, Stevens JC. Practice parameter: diagnosis of dementia (an evidencebased review). Report of the Quality Standards Subcommittee of the American Academy of Neurology. Neurology. 2001;56:1143-53.

26. Holmes C, Cairns N, Lantos P, Mann A. Validity of current clinical criteria for Alzheimer's disease, vascular dementia and dementia with Lewy bodies. Br J Psychiatry. 1999;174:45-50.

27. Gold G, Giannakopoulos P, Montes-Paixao Junior C, Herrmann FR, Mulligan R, Michel JP, Bouras C. Sensitivity and specificity of newly proposed clinical criteria for possible vascular dementia. Neurology. 1997;49:690-4

28. Staehelin H, Ermini-Fuenfschilling D, Grunder B, Krebs-Roubicek E, Monsch A, Spiegel R. Die Memory Klinik. Therapeutische Umschau. 1989;46:72-77.

29. Staehelin H, Monsch A, Spiegel R. Early diagnosis of dementia via a two-step screening and diagnostic procedure. Int Psychogeriatr. 1997;9:123-130.

30. Hachinski VC, Iliff LD, Zilhka E, Du Boulay GH, McAllister VL, Marshall J, Russell RW, Symon L. Cerebral blood flow in dementia. Arch Neurol. 1975;32:632-7. 
31. Association AP. Diagnostic and statistical manual of mental disorders. 4th ed. Washington DC. American Psychiatric Association. 1994

32. McKhann G, Drachman D, Folstein M, Katzman R, Price D, Stadlan EM. Clinical diagnosis of Alzheimer's disease: report of the NINCDS-ADRDA Work Group unde the auspices of Department of Health and Human Services Task Force on Alzheimer's Disease. Neurology. 1984;34:939-44.

33. Roman GC, Tatemichi TK, Erkinjuntti T, Cummings JL, Masdeu JC, Garcia JH, Amaducci L, Orgogozo JM, Brun A, Hofman A, et al. Vascular dementia: diagnostic criteria for research studies. Report of the NINDS-AIREN International Workshop. Neurology. 1993;43:250-60.

34. Gallyas F. Silver staining of Alzheimer's neurofibrillary changes by means of physical development. Acta Morphol Acad Sci Hung. 1971;19:1-8.

35. Dickson D. Neurodegeneration: the molecular pathology of dementia and movement disorders. ISN Neuropath Press. 2003:414.

36. Drach LM, Steinmetz HE, Wach S, Bohl J. High proportion of dementia with Lewy bodies in the postmortems of a mental hospital in Germany. Int J Geriatr Psychiatry. 1997;12:301-6.

37. Lim A, Tsuang D, Kukull W, Nochlin D, Leverenz J, McCormick W, Bowen J, Teri L, Thompson J, Peskind ER, Raskind M, Larson EB. Clinico-neuropathological correlation of Alzheimer's disease in a community-based case series. J Am Geriatr Soc. 1999;47:564-9.

38. Lopez OL, Litvan I, Catt KE, Stowe R, Klunk W, Kaufer DI, Becker JT, DeKosky ST. Accuracy of four clinical diagnostic criteria for the diagnosis of neurodegenerative dementias. Neurology. 1999;53:1292-9.

39. Moroney JT, Bagiella E, Desmond DW, Hachinski VC, Molsa PK, Gustafson L, Brun A, Fischer P, Erkinjuntti T, Rosen W, Paik MC, Tatemichi TK. Meta-analysis of the Hachinski Ischemic Score in pathologically verified dementias. Neurology. 1997:49:1096-105.

40. Ulrich J, Probst A, Wuest M. The brain diseases causing senile dementia. A morphological study on 54 consecutive autopsy cases. J Neurol. 1986;233:118-22.

41. Kalaria RN, Kenny RA, Ballard CG, Perry R, Ince P, Polvikoski T. Towards defining the neuropathological substrates of vascular dementia. J Neurol Sci 2004;226:75-80

42. Braak H, Braak E. Neuropathological staging of Alzheimer-related changes. Acta Neuropathol 1991;82:239-259.

43. Mirra SS, Heyman A, McKeel D, Sumi SM, Crain BJ, Brownlee LM, Vogel FS, Hughes JP, van Belle G, Berg L and participating CERAD neuropathologists. The consortium to establish a registry for Alzheimer's disease (CERAD). II Standardization of the neuropathological assessment of Alzheimer's disease. Neurology 1991;41:479-486.

44. National Institute on Aging and Reagan Institute Working Group on diagnostic criteria for the neuropathological assessment of Alzheimers disease. Consensus recommendations for the postmortem diagnosis of Alzheimer's disease. Neurobiol recommendations for the
Aging 1997;18 S4:S1-S2.

45. Levy R. Aging-associated Cognitive Decline. The Working Part of the International Psychogeriatric Association in collaboration with the World Health Organization. Intern Psychogeriatr 1994;6:63-68. 